

\title{
Experimental and numerical analysis of impeller recirculation: inlet guide vanes stagger angle effects and rotating disturbances interaction
}

Nicolas Poujol, Pierre Duquesne, Isabelle Trébinjac

\section{To cite this version:}

Nicolas Poujol, Pierre Duquesne, Isabelle Trébinjac. Experimental and numerical analysis of impeller recirculation: inlet guide vanes stagger angle effects and rotating disturbances interaction. 14th European Conference on Turbomachinery Fluid dynamics \& Thermodynamics, Apr 2021, Gdansk, Poland. hal-03257363

\section{HAL Id: hal-03257363 \\ https://hal.science/hal-03257363}

Submitted on 10 Jun 2021

HAL is a multi-disciplinary open access archive for the deposit and dissemination of scientific research documents, whether they are published or not. The documents may come from teaching and research institutions in France or abroad, or from public or private research centers.
L'archive ouverte pluridisciplinaire $\mathbf{H A L}$, est destinée au dépôt et à la diffusion de documents scientifiques de niveau recherche, publiés ou non, émanant des établissements d'enseignement et de recherche français ou étrangers, des laboratoires publics ou privés.

\section{(이) $\$$}

Distributed under a Creative Commons Attribution - NonCommercial - NoDerivatives| 4.0 


\title{
EXPERIMENTAL AND NUMERICAL ANALYSIS OF IMPELLER RECIRCULATION: INLET GUIDE VANES STAGGER ANGLE EFFECTS AND ROTATING DISTURBANCES INTERACTION
}

\author{
N. Poujol $^{1,2}$ - P. Duquesne $e^{2}-$ I. Trébinjac ${ }^{2}$
}

${ }^{1}$ Safran Helicopter Engines, Bordes, France, nicolas.poujol@ec-lyon.fr

${ }^{2}$ Laboratoire de Mécanique des Fluides et d'Acoustique, Ecole Centrale de Lyon, Ecully, France

\begin{abstract}
In centrifugal compressors, areas of reversed flow frequently develop near the endwalls at partial rotation speed. The present contribution investigates such a recirculated flow zone in an aeronautical research centrifugal compressor stage designed and built by Safran Helicopter Engines. The compressor stage is fitted with Inlet Guide Vanes (IGV). The effects of the change in the IGV stagger angle on the occurrence and development of the recirculation area is analyzed thanks to both experimental (pressure sensors) and numerical (RANS) results. The recirculation zone, born in the inducer, extends towards the hub and upstream as the compressor is throttled for the three IGV stagger angles. At high IGV stagger angle, the recirculation zone extends downstream until it reaches the impeller trailing edge. Furthermore, the impact of the onset of the recirculation on the amplitude and circumferential velocity of rotating disturbances (or instabilities) in the inducer is also described.
\end{abstract}

\section{KEYWORDS}

CENTRIFUGAL COMPRESSOR, RECIRCULATION, ROTATING INSTABILITIES, INLET GUIDE VANES

\section{NOMENCLATURE}

\section{Latin}

A

$\mathrm{h}$

$\dot{\mathrm{m}}$

$\mathrm{V}$

Greek Symbols

$\pi$

$\varphi$

$\Omega$

Subscripts

C

IMP. or R

RD

ref

std

$\mathrm{m}$
Alternate rate

Span height

Mass flow

Absolute Velocity

Absolute flow angle

Pressure ratio

IGV stagger angle

Rotation speed

Compressor (IGV + IMP. +RD)

Impeller

Radial Diffuser

Reference (value)

Standard

meridional

\section{Superscripts}

S-S Static to static

t-s Total to static

Abbreviations

BPF Blade Passing Frequency

IGV Inlet Guide Vanes

LE Leading Edge

MXPL Mixing Plane

ONERA Office National d'Etudes et de

Recherches Aérospatiales

RANS Reynolds-Averaged Navier-Stokes

RI Rotating instabilities (disturbances)

SP Stability parameter

SafranHE Safran Helicopter Engines

TE Trailing Edge 


\section{INTRODUCTION}

Engine manufacturers try to enhance the versatility of helicopter turboshafts. As a result, the operating range of compressors should be extended while preserving high efficiency. Two methods are used to extend the stable operating range: (i) gain insight on the path to surge or (ii) push towards lower mass flow rates the onset of deep surge and local instabilities (which allows an increase of the surge margin). These two methods require a good understanding of mechanisms of local instabilities and their triggering.

Numerous local instabilities can develop in a centrifugal compressor stage before surge. This research work focuses on two instabilities growing in the impeller: rotating disturbances (or rotating instabilities) in the inducer and recirculation in the impeller.

Rotating disturbances correspond to rotating swirl zones whose intensity and frequency are continuously varying. Rotating disturbances have been firstly observed and distinguished from rotating stall by Baumgartner et al. (1995) in a multi-stage axial compressor. Mailach et al. (2001) observe experimentally that the fluctuations of the tip leakage vortex are responsible for the generation of the rotating disturbance. März et al. (2001), Inoue et al. (2004) confirm the role of the tip leakage vortex in the origin of rotating disturbances by experimental and numerical means. Furthermore, rotating disturbances do not impact the performance of the compressor. Rotating disturbances have been less frequently observed in centrifugal compressors. They were more recently observed by Sun et al. (2018) and He and Zheng (2018).

At partial rotation speed, a boundary layer flow separation might develop at the shroud in the inducer (observed mainly in compressors for automotive application). This separation can induce a stable area of reversed flow all around the circumference named recirculation. Harley et al. (2014) and Stuart et al. (2017) have shown numerically that this recirculation born in the inducer can extend to the trailing edge of the impeller. The blockage zone at the trailing edge causes an acceleration of the flow in the active zone (defined in Fig. 5) and therefore a decrease of the incidence on the radial diffuser.

Concerning the experimental detection of impeller recirculation, Tamaki et al. (2016) observed the recirculation occurrence in the inducer with an oil film dumped on the shroud. Diez et al. (2014) reported a higher static pressure than the total pressure measured upstream the leading edge at the shroud. This anomaly is explained by the authors by a bad alignment of the total pressure probe when the flow direction is reversed.

The short distance between the inlet guide vanes (IGV) or a structural obstacle and the impeller in new generation centrifugal compressors brings forth the question of the interaction between the IGV and the upstream extension of the recirculation. Inlet fins are mounted in a centrifugal compressor pipe by Tamaki et al. (2016) to remove the preswirl induced by the recirculation. An extension of the operating range is observed. This is corroborated by the parametric study on the distance IGV-impeller of $\mathrm{Li}$ et al. (2018) which also showed that the surge margin improvement also depends on the backflow topology inside the IGV.

Both the rotating disturbances and the recirculation appear in the inducer of the studied impeller, therefore one can reflect upon the interaction between these two instabilities. To the author's knowledge, no work on this interaction in centrifugal compressors has been published. In a low speed axial fan, Kameier et al. (1997) observed a lock-in of the rotating speed of rotating disturbances synchronized with the onset of a whole annulus recirculation.

The present work aims at investigating experimentally and numerically the effect of the IGV stagger angle on the extension of recirculation at a partial rotation speed in a new generation centrifugal compressor. This study also focuses on the interaction between rotating disturbances and the recirculation.

First, the test case, the experimental and numerical setups are described. The numerical simulations are then assessed against the experimental data. Then, the development of the inducer 
recirculation is numerically described at 3 IGV stagger angles. Lastly, a particular behavior of rotating disturbances in presence of the recirculation is experimentally described.

\section{TEST CASE}

The test case is a research centrifugal compressor stage designed and manufactured by Safran Helicopter Engines. The compressor stage includes four blade rows: axial inlet guide vanes (IGV), an unshrouded backswept splittered impeller (IMP.), a splittered vaned radial diffuser (RD) and axial outlet guide vanes (OGV). A meridional scheme of the compressor is provided in Fig. 1.

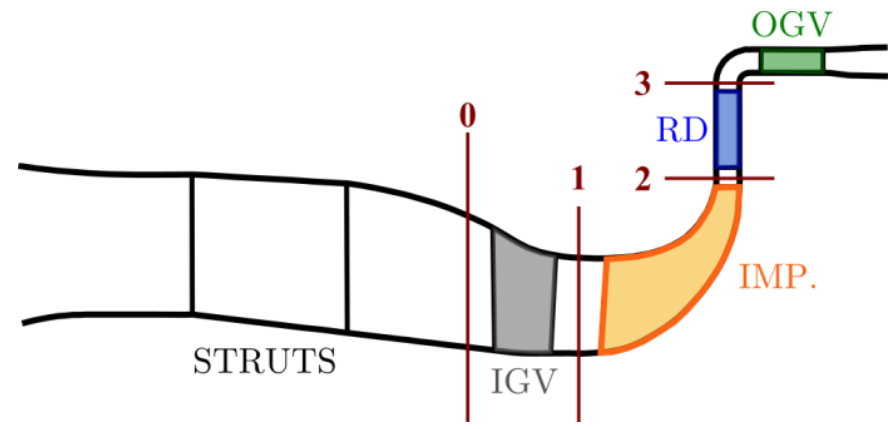

Figure 1: Meridional view of the compressor

The overall stage total to static pressure ratio at the design point is around 4. The Mach number based on the peripheral velocity and sound velocity at the exit radius of the impeller is around 1.2. The investigated rotation speed reported in this work is low and the IGV stagger angle can be set to 0,20 and $40^{\circ}$ (positive pre-swirl).

\section{EXPERIMENTAL SETUP}

In the framework of the FLORA project from Clean Sky 2 Joint Undertaking, the centrifugal compressor stage was mounted on the 1MW test rig of Ecole Centrale de Lyon. More than a hundred steady pressure measurements and almost 20 thermocouples are exploited for the monitoring and the performance measurements. A diaphragm flowmeter, located at the test rig inlet, measures the mass flow with a great accuracy $( \pm 0.11 \%$ at the design point $)$. More details about measurements and the methodology of performance calculation are broadly given in previous work: Moënne-Loccoz et al. (2020) and Poujol et al. (2020).

Furthermore, 54 unsteady pressure sensors (from Kulite Semiconductor Product Inc.) are distributed over the entire stage in order to capture instabilities. These unsteady pressure sensors are flush-mounted in the hub and shroud. To capture phenomena at frequencies around tens of blade passing frequency, the protection grids are removed in order to maximize the natural frequency of the probes. The data acquisition frequency is $500 \mathrm{kHz}$. An analogue high-frequency cut filter $(>250 \mathrm{kHz})$ is used to delete parasites due to sensors resonance $(440 \mathrm{kHz})$ and electromagnetic radiations (700 $\mathrm{kHz}$ ). The average value of the uncertainties of the fluctuations is less than $0.7 \%$ of the peak-to-peak pressure fluctuation of the signal. Six of these unsteady pressure sensors are circumferentially distributed at the shroud at the impeller inlet ( $1 \mathrm{~mm}$ upstream the impeller leading edge), the distribution is depicted in Fig. 2.

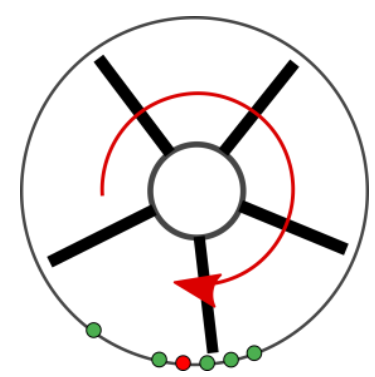

Figure 2: Distribution of the unsteady pressure sensors at the impeller inlet 


\section{NUMERICAL SETUP}

Steady simulations (RANS) are run with the elsA software (Cambier et al., 2011) developed at ONERA. The code elsA uses a cell-centered finite volume method.

From the experimental results (Moënne-Loccoz et al., 2019), it can be stated that the timedependent phenomena develop essentially in the radial diffuser. It is thus justified to carry out analyses of the recirculation which develops in the front part of the impeller from steady simulations. This work also deals with rotating disturbances which obviously cannot be described with steady simulations. But (i) it is known that rotating disturbances do not change the operating point (Mailach et al., 2001) and (ii) they are only described with experimental tools in the following. In addition, many operating points are simulated, which would be prohibitively expensive with unsteady simulations.

The single-passage mesh includes around 15 million cells distributed as follows: 1.5 million for the air inlet and IGV, around 5 million for the impeller, around 5 million for the radial diffuser and 4 million for OGV. The mesh has been built by SafranHE with in-house best practices and the $y+$ values in the whole domain are between 1 and 10 .

The turbulence model used is the k-1 model of Smith (1994) which does not need a particular treatment for the viscous sublayer. Furthermore, this model is barely sensitive to the first cell size.

Concerning numerical schemes, the second-order Roe upwind spatial scheme with Harten's entropic correction is used. Regarding time integration, a first-order backward-Euler scheme is used with an upwind implicit phase including a lower-upper decomposition. The CFL number is set to 40 .

Regarding boundary conditions, non-slip and adiabatic conditions are applied to the walls. In each row, periodic azimuthal boundaries are imposed. Velocity angles, the standard stagnation pressure and temperature are imposed at the inlet. A value of static pressure at mid-span completed by a radial equilibrium is applied as the outlet condition. Mixing planes using Riemann invariants are used for the IGV-impeller and the impeller-diffuser interfaces. According to Schreiber (2017), the well established recirculation is axisymmetric. Therefore the numerical prediction of the established recirculation zone is not impacted by the mixing plane at the IGV-impeller interface.

\section{ASSESSMENT OF NUMERICAL SIMULATION VS EXPERIMENTAL DATA}

Numerical simulations are run to investigate in depth the impeller recirculation. The use of mixing planes is considered valid because the recirculation reveals to be circumferentially independent outside a blade row. The accuracy of numerical simulations is assessed by the pressure ratios of the stage and components measured. The total to static pressure ratio of the whole compressor, the total to static pressure ratio of the IGV and the impeller together and the static to static pressure ratio of the radial diffuser are plotted in Fig. 3 for all IGV stagger angles $\varphi$. The numerical static pressure field is probed according to the position of experimental probes in order to allow a fair comparison. It means that instead of using an averaged pressure a local pressure is taken at the identical position as the probe is located. The contributions of the IGV and the impeller to the whole pressure ratio are not splitted because the recirculation extends upstream into the IGV channel near surge and therefore it induces a discontinuity in the IGV pressure losses calculated (and the impeller pressure ratio). However, this grouping of IGV and impeller is not compromising since the IGV pressure losses are less than $0.5 \%$ and vary slightly between all operating points at this low rotation speed. 

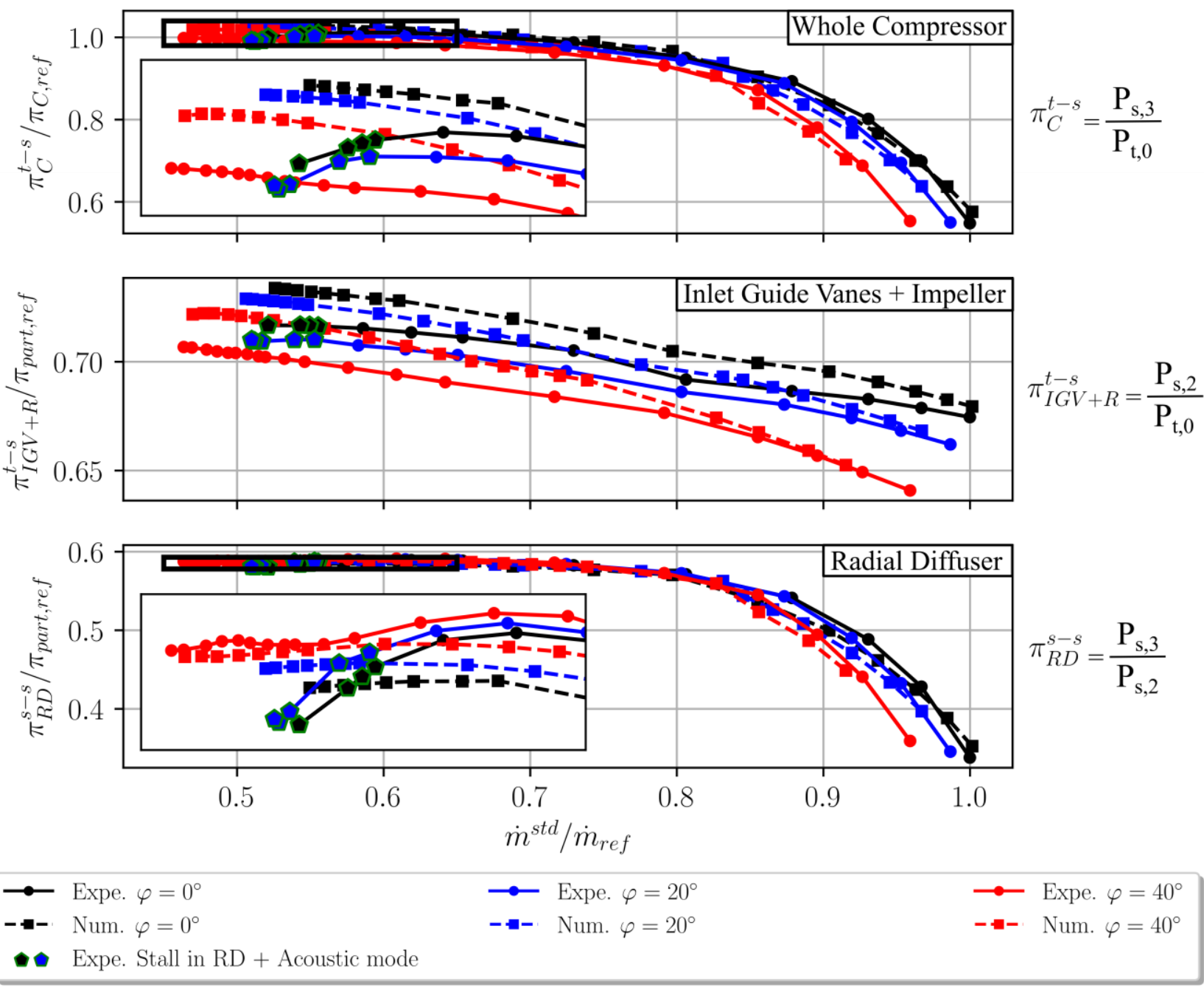

Figure 3: Comparison of numerical and experimental pressure ratios of the stage and components

The discrepancies of numerical pressure ratios compared to experimental values are at most $2.2 \%$ for the whole stage, $2.4 \%$ for the IGV/impeller and $0.8 \%$ for the radial diffuser. The experimental uncertainty is estimated around $0.05 \%$. However, these discrepancies are not uncommon for a centrifugal compressor at partial rotation speed and low enough to ensure the accuracy of the numerical simulations.

The whole compressor and the radial diffuser are unstable (positive slope) in the measurements whereas they are still stable in the numerical simulations (slightly negative slope). This discrepancy is observed for operating points where a lock-in of a stall in the radial diffuser and the main acoustic mode of the test bench occurs (described by Moënne-Loccoz et al., 2019). This lock-in does not occur in numerical simulations for two reasons: simulations are steady and the pipe network upstream and downstream the compressor is not included. This stall occurs in the radial diffuser, therefore the impact on the recirculation analysis in the impeller can be considered weak. 


\section{A COMMON BEHAVIOR OF THE INDUCER RECIRCULATION AT THE 3 IGV STAGGER ANGLE}

First, it is worth noting that the flow regime upstream the impeller is similar between the 3 IGV stagger angle. The absolute flow angle at the IGV outlet (before the mixing plane between the IGV row and the impeller) is extracted from numerical simulation. The difference between the IGV stagger angle and the absolute flow angle is similar between all stagger angles and very low (less than $4^{\circ}$ at the worst case near surge). The flow on the IGV is not separated at the IGV stagger angle of $40^{\circ}$.

The analysis of the inducer recirculation is reported at nine operating conditions. At each IGV stagger angle, three operating points are chosen to be representative for the recirculation establishment: before the establishment, well established and before surge when the recirculation zone size is maximal. Operating points are given in Table 1.

The absolute value of meridional velocity, extracted from numerical simulations, is plotted in a meridional view for OP1 to OP3 in Fig. 4. The positions of the leading edge and the trailing edge of rows and of the mixing planes are also plotted in Fig. 4. The recirculation zone corresponds to the low meridional velocity zone at the shroud (in blue in Fig. 4). As shown in Fig. 5b adapted from Harley et al. (2014), the negative meridional velocity zone radial extension is about half that of the recirculation zone. For all stagger angles, if the compressor is throttled, the flow rate decreases and the pressure ratio of the IGV and the impeller remains relatively constant. This evolution corresponds to a less and less energetic boundary layer, on which acts the same adverse pressure gradient. As a result, the inducer recirculation extends towards the inlet guide vanes. The recirculation is able to go upstream the mixing plane between the impeller and the IGV because it is circumferentially similar downstream the mixing plane.

As shown in Fig. 4, the recirculation zone does not extend significantly upstream from OP2 to OP3 (the same tendency can be observed at all IGV stagger angles). This lack of upstream extension is the consequence of the aerodynamic blockage induced by IGV. Previous numerical studies on the same compressor have shown that the recirculation extends far upstream without IGV as already observed by some works quoted in the introduction. However, the radial extent of the recirculation zone changes considerably from the establishment of the recirculation to surge. The radial profile of the meridional velocity downstream the mixing plane is plotted in Fig. 5a. At this extraction plane, the negative meridional velocity zone extends radially on $7 \%$ of span height at OP2 and on $13 \%$ at OP3. Similar radial extension is observed at the IGV stagger angles of $20^{\circ}$ and $40^{\circ}$.

\begin{tabular}{|c|c|c|c|}
\hline Operating point & IGV stagger angle & $\dot{m}^{\text {std }} / \dot{m}_{\text {ref }}$ & Location/ Flow Topology \\
\hline OP1 & $0^{\circ}$ & 0.9 & Before establishment \\
\hline OP2 & $0^{\circ}$ & 0.74 & Well established \\
\hline OP3 & $0^{\circ}$ & 0.53 & Near Surge, Recirculation maximum size \\
\hline OP4 & $20^{\circ}$ & 0.89 & Before establishment \\
\hline OP5 & $20^{\circ}$ & 0.7 & Well established \\
\hline OP6 & $20^{\circ}$ & 0.51 & Near Surge, Recirculation maximum size \\
\hline OP7 & $40^{\circ}$ & 0.83 & Before establishment \\
\hline OP8 & $40^{\circ}$ & 0.62 & Well established \\
\hline OP9 & $40^{\circ}$ & 0.47 & Near Surge, Recirculation maximum size \\
\hline
\end{tabular}

Table 1: Definition of operating points numerically investigated 


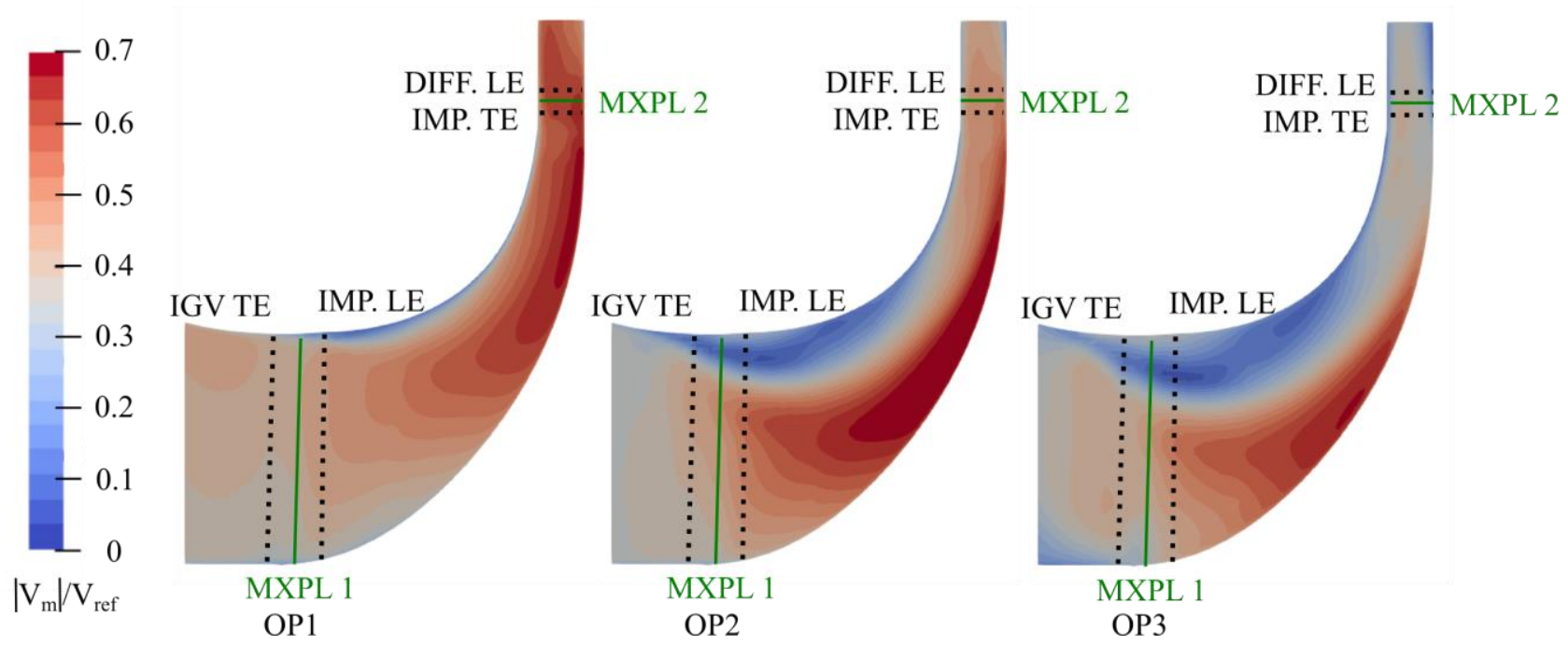

Figure 4: Meridional views of the meridional velocity representative for the recirculation establishment at OP1 to OP3 with an IGV stagger angle of $0^{\circ}$
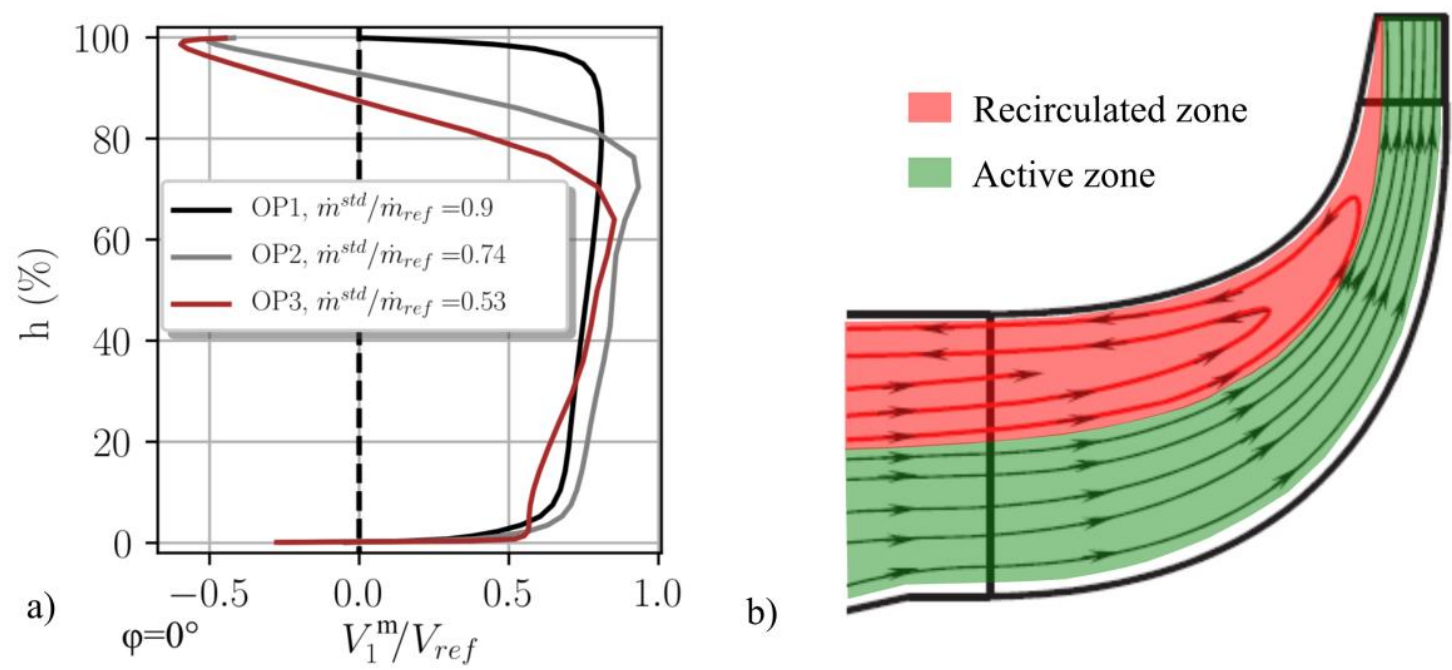

Figure 5: a) Axial velocity profiles upstream the impeller (at mixing plane 1) at IGV stagger angle of $\left.0^{\circ}, b\right)$ Topology of recirculation zone and active zone (adapted from Harley et al.)

\section{A PARTICULAR BEHAVIOR OF THE RECIRCULATION AT IGV STAGGER ANGLE OF $40^{\circ}$}

While the extension of the recirculation downstream is small for IGV stagger angles of $0^{\circ}$ and $20^{\circ}$, it is significant with an IGV stagger angle of $40^{\circ}$ near surge (OP 9) as shown in Fig. 6 (see red ellipse). The profile of the meridional velocity downstream the mixing plane 2 (MXPL2) is plotted for operating points at stagger angles of $0^{\circ}$ and $40^{\circ}$ in Fig. 7. These profiles have classic shapes for the IGV stagger angle of $0^{\circ}$ but at IGV stagger angle of $40^{\circ}$, a negative meridional velocity zone extends on $5 \%$ of span height. 


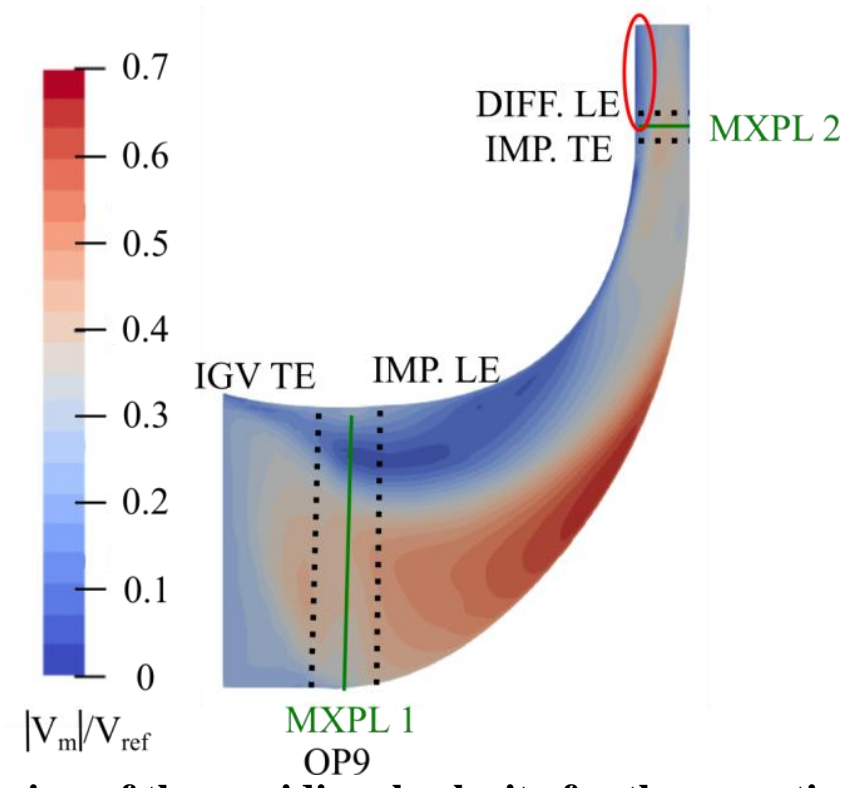

Figure 6: Meridional view of the meridional velocity for the operating point near surge at IGV stagger angle of $40^{\circ}$


Figure 7: Radial velocity profiles downstream the impeller (at mixing plane 2) at IGV stagger angles of $0^{\circ}$ and $40^{\circ}$

This recirculation zone induces a redistribution of the mass flow rate along the span height. As a result, the meridional velocity (radial velocity in the exducer) increases from the hub to the height below the recirculation zone near surge. This increase of meridional velocity in the healthy zone (below the recirculation zone) corresponds to a decrease of the incidence on the radial diffuser shown in Fig. 8 (bottom).

The alternate rate A, experimentally measured, and the absolute flow angle $\alpha_{2}$, numerically computed, at the diffuser leading edge are plotted against the standard mass flow rate for the IGV stagger angle of $40^{\circ}$ in Fig. 8 (top). The angle $\alpha_{2}$ is derived from an average on a 2D radius slice at the diffuser inlet. The whole span and the whole pitch are considered for the averaging. First the radial and the tangential velocity components are averaged with area weight and then the angle $\alpha_{2}$ is computed from these values. The definition and the meaning of the alternate rate $\mathrm{A}$, an original indicator introduced because of a particular flow topology in the radial diffuser of this compressor stage, is given by Moënne-Loccoz et al. (2020). A high alternate rate corresponds to a flow topology different over two adjacent channels of the radial diffuser: one channel is stalled whereas the other is free (pattern steady in time and in space). A null alternate rate corresponds to a periodic flow topology: the flow is similar in each channel. Previous work (Poujol et al., 2020) has shown that the 
alternate rate is proportional to the absolute flow angle which cannot be measured on the test bench. A significance level of 0.007 (due to discretization errors, see Moënne-Loccoz et al.) below which the flow topology can be considered as periodic is plotted with a dashed line in Fig. 8.

If the compressor is throttled towards surge, the absolute flow angle at the diffuser leading edge continuously increases in a classic compressor. In this case, there is a slight decrease of the absolute flow angle near surge which coincides well with a reduction, experimentally observed, of the alternate rate. The transition operating point between the two trends of the absolute flow angle is marked with a red dotted line, a very good agreement between the experimental and numerical analysis is observed.

This decrease of incidence on the radial diffuser is obviously due to the extension of the impeller recirculation up to the radial diffuser leading edge. The flow is thus better aligned with the diffuser leading edge which is favorable for the stability. The compressor surge limit is pushed towards lower mass flow rate.
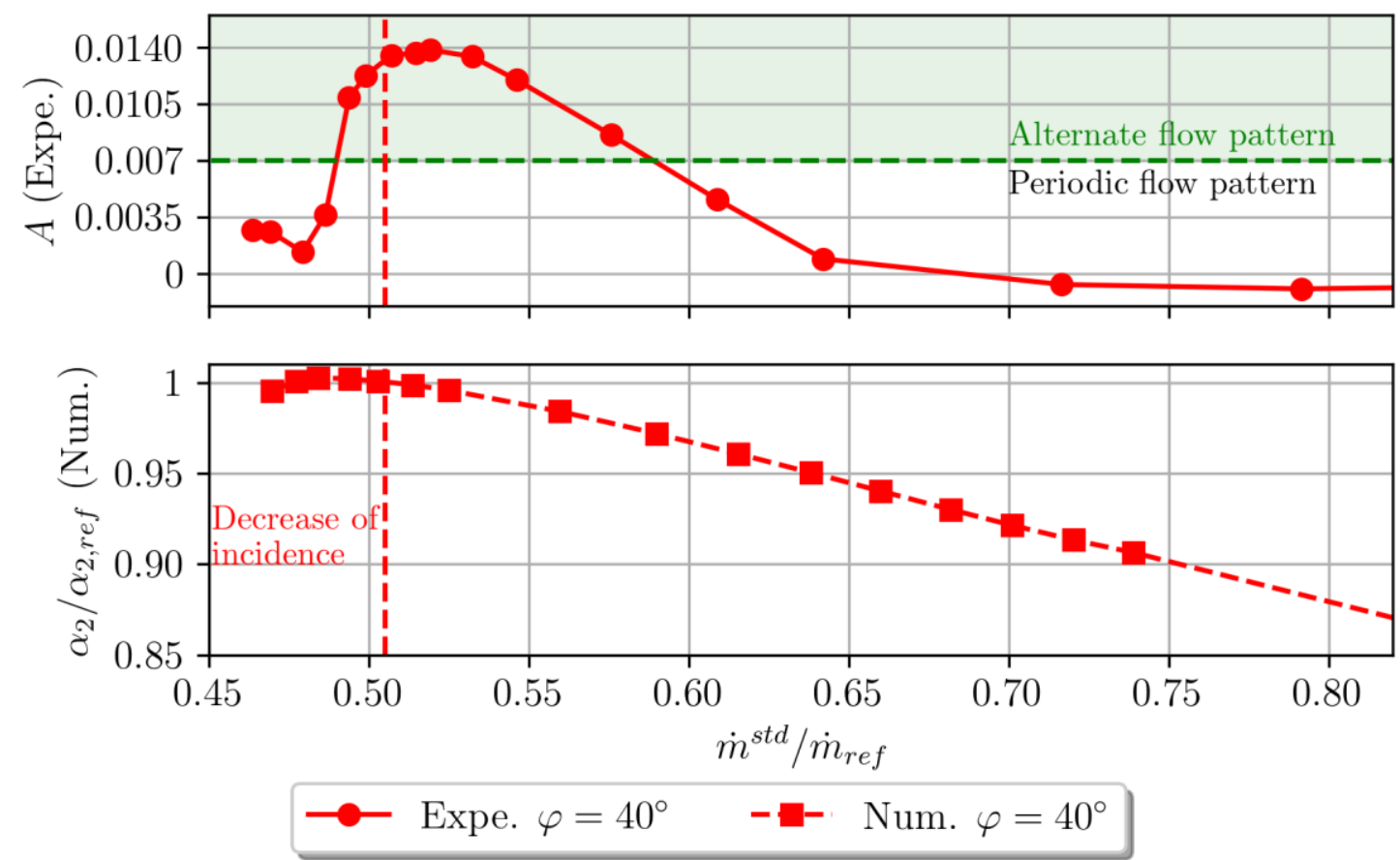

Figure 8: Experimental alternate rate and numerical absolute flow angle at the diffuser inlet at IGV stagger angle of $\mathbf{4 0}{ }^{\circ}$

\section{EXPERIMENTAL OBSERVATION OF ROTATING DISTURBANCES}

Rotating disturbances (or instabilities) are observed with the 6 circumferentially distributed unsteady pressure sensors embedded at the shroud at impeller inlet (see Fig. 2). An experimental description of these rotating disturbances on the same compressor is given by Poujol et al. (2020), it is mainly shown that their occurrence is conditioned by the relative flow angle at the tip of the leading edge of the impeller. The rotation speed of rotating disturbances is calculated with a cross-correlation of the pressure signals of sensors. In Fig. 9, the standard deviation of the pressure fluctuations on one sensor (at the top), marked in red in Fig. 2, and the rotation speed of the rotating disturbances (at the bottom) are plotted against the standard mass flow rate.

Concerning the stagger angles of $0^{\circ}$ and $20^{\circ}$, two behaviors of rotating disturbances are distinguished:

The first one occurs not far from choke up to the operating point where the standard deviation of pressure fluctuations reaches a local maximum (corresponding to large circle markers in Fig. 9). In this operating range, an increase in amplitude of rotating disturbances as the mass flow is reduced explains the increase of the standard deviation. The rotation speed of these rotating disturbances is between $40 \%$ and $60 \%$ of the impeller rotation speed. 
The second behavior occurs from the standard deviation local maximum to the last stable operating point. In this range, a lock-in of the rotation speed of rotating disturbances at around $70 \%$ of the impeller rotation speed occurs. This lock-in is suspected of being the consequence of the establishment of the recirculation in the inducer. Experimental clues (in addition to numerical evidences previously shown) such as an abrupt increase of the shroud temperature inside the inducer support this assumption. The standard deviation of the pressure fluctuations increases near surge. This increase coincides with the occurrence of the lock-in of a stall in the radial diffuser and the main acoustic mode of the test bench, this frequency is clearly distinguished from the characteristic frequency of rotating disturbances (with an order of magnitude of several $\mathrm{kHz}$ ).

Concerning the stagger angle of $40^{\circ}$, these two behaviors exist but a third behavior near surge appears. Indeed, the standard deviation of the pressure signals remains constant but the rotation speed of rotating disturbances locks on around $90 \%$ of the impeller rotation speed near surge. This behavior of rotating disturbances is suspected to be the result of a change of the inducer recirculation.
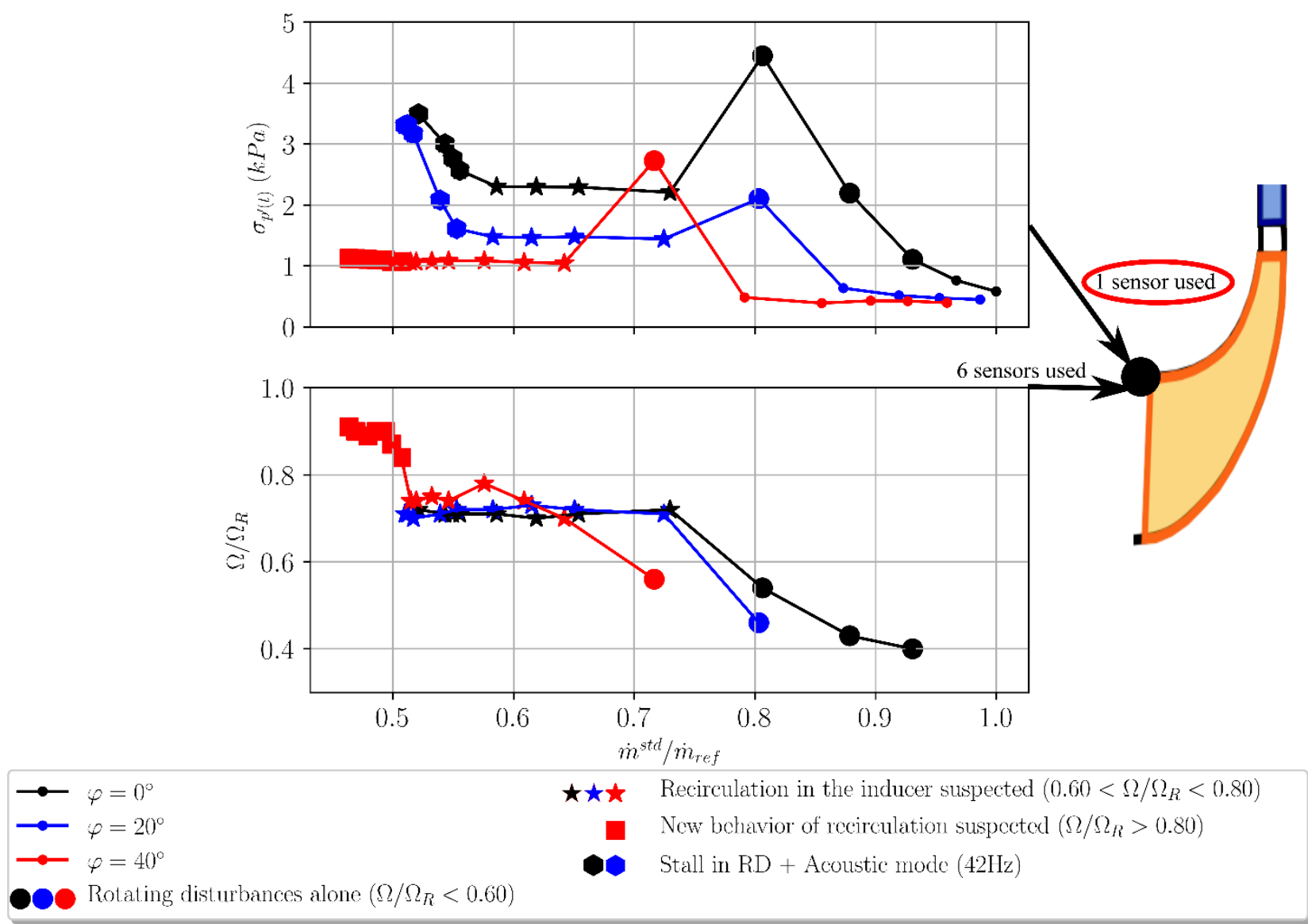

Figure 9: Experimental characterization of rotating disturbances and prospective interaction with recirculation

\section{THE INTERACTION BETWEEN ROTATING DISTURBANCES AND RECIRCULATION}

The interaction between rotating disturbances and recirculation in the inducer is investigated in details by analyzing the experimental unsteady pressure measurements in light of the numerical observation of the recirculation. Pressure spectra are computed from pressure measurements located upstream the impeller leading edge at the shroud for stable operating points from choke to surge. The whole measurement lasting 4 seconds is split into portions of 20 impeller rotations. The phase average is substracted to the signal for each portion in order to remove the synchronous phenomena such as the blade passing. Pressure spectra obtained are then averaged with each other to provide a 
representative pressure spectrum for each operating point plotted in Fig. 10 for the IGV stagger angle of $0^{\circ}$. This IGV stagger angle is representative of the recirculation establishment process.

This processing methodology shows the frequency content associated with the standard deviation of the pressure fluctuations plotted in Fig. 9. At the choked operating point (blue spectrum), there are no pressure fluctuations because of the lack of rotating disturbances and recirculation. At the last operating point before the establishment of the recirculation (green spectrum), the characteristic bump of rotating disturbances (with strong pressure fluctuations) is observed. Concerning operating points where the recirculation is established (red and brown spectra), the bump becomes weak and does not change anymore until surge. This constant amplitude of rotating disturbances due to recirculation corresponds to the lock-in of the rotation speed of rotating disturbances at around $70 \%$ of the impeller rotation speed shown in Fig. 9. It is believed that these constant characteristics of rotating disturbances are induced by the recirculation. The establishment of recirculation in the inducer near the shroud stops the evolution of the flow field.

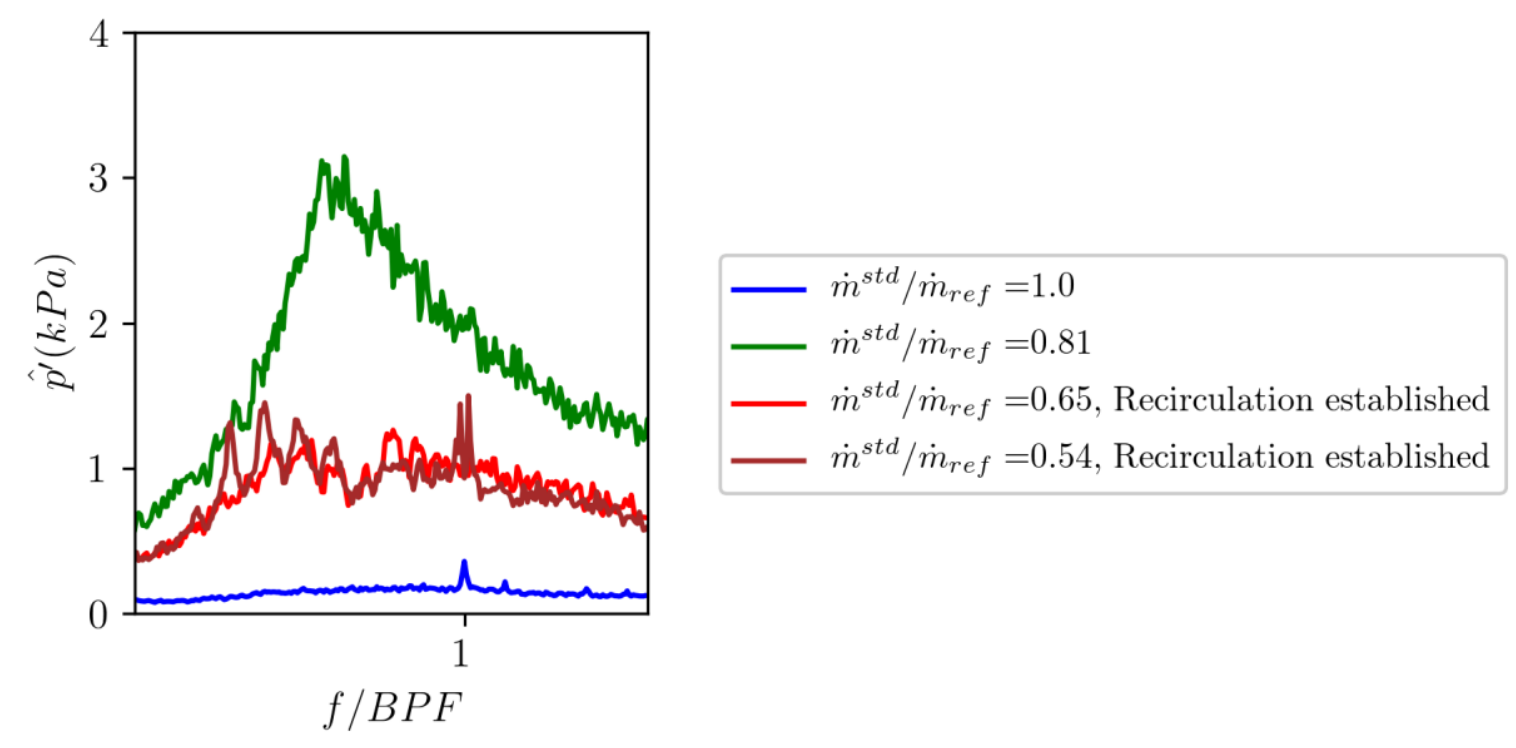

Figure 10: Experimental unsteady pressure spectra registered at the impeller leading edge at IGV stagger angle of $0^{\circ}$

The same analysis on a continuous throttling from maximum efficiency operating point to deep surge is carried out at IGV stagger angle of $0^{\circ}$. The same methodology for computing the pressure spectra is used but these last ones are then juxtaposed to study the temporal evolution of rotating disturbances. This evolution is plotted in Fig. 11 with a double $\mathrm{x}$-axis being rotations before surge at the bottom and the standard mass flow rate at the top. The last experimental and numerical operating points without recirculation and the first operating points where the recirculation is established are also plotted in Fig. 11.

A sudden decrease of amplitude related to the recirculation establishment is clearly observed around $-16,800$ rotations before surge. Moreover, this sudden decrease corresponds to a mass flow rate in the range of the recirculation establishment identified by numerical simulations and experimental measurements on stable operating points. As a result, this unsteady analysis corroborates the steady analysis and shows that the lock-in of the rotating disturbances with the recirculation establishment is immediate. 


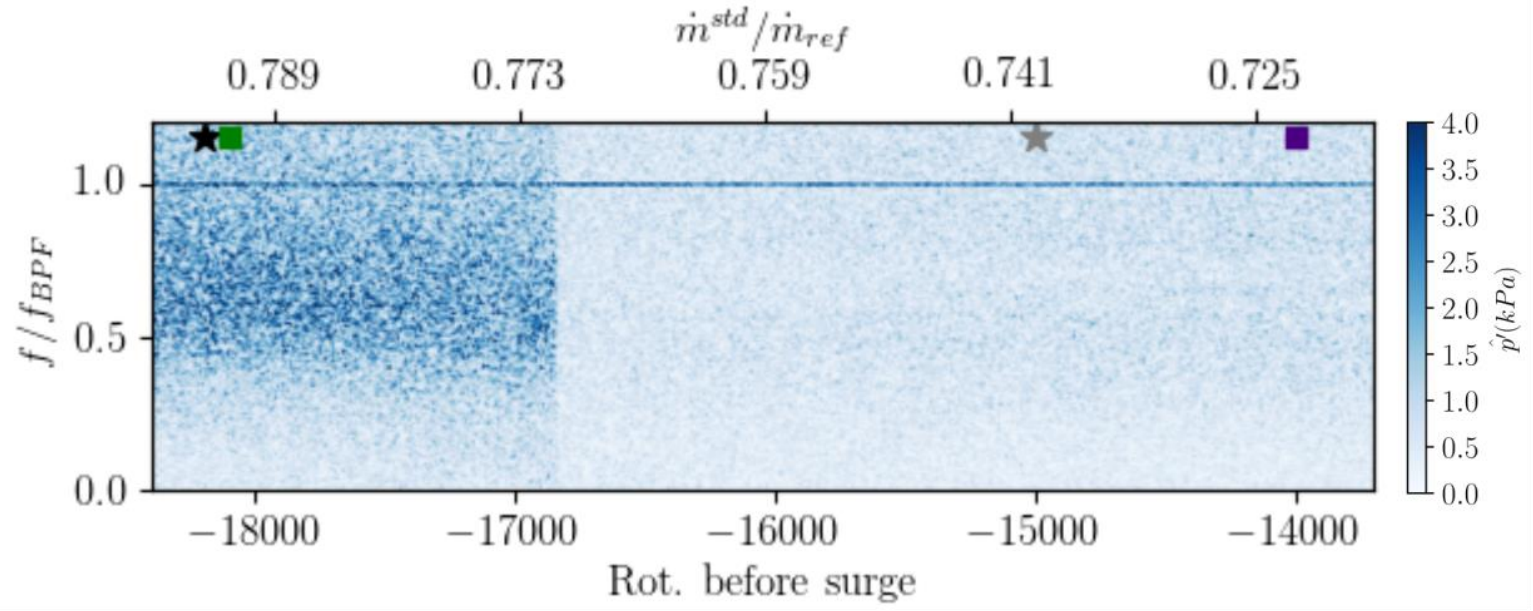

Figure 11: Evolution of rotating disturbances amplitude during a continuous throttling at IGV stagger angle of $0^{\circ}$

\section{CONCLUSIONS}

An impeller recirculation is analyzed thanks to RANS simulations and experimental results. Its behavior is studied in regard with the IGV stagger angle change. Its interaction with rotating disturbances is proved.

As long as the IGV stagger angle is below $20^{\circ}$, the recirculation extension remains unchanged both in the meridional and in the radial directions.

At high IGV stagger angle $\left(40^{\circ}\right)$, the recirculation zone extends considerably and reaches the diffuser leading edge. This leads to a decrease of the incidence on the radial diffuser near surge. The flow is thus better aligned with the diffuser leading edge which is favorable for the stability. The compressor surge limit is pushed towards lower mass flow rate.

A complex interaction between rotating disturbances and the impeller recirculation is experimentally detected with both steady (stable operating point measurements) and unsteady analysis (continuous throttling). The amplitude and the rotation speed of these disturbances promptly lock on constant values as soon as the recirculation is established. This lock-in is thought to be induced by the recirculation which freezes the flow field near shroud.

\section{ACKNOWLEDGEMENTS}

The authors would like to thank Pierre Laucher, Sebastien Goguey, Gilbert Halter and Benoit Paoletti for manufacturing the test bench and supporting the measurements.

Nicolas Rochuon, Nicolas Buffaz, Emmanuel Bénichou, Victor Moënne-Loccoz and Julissa Grondin are kindly thanked for their previous studies.

The authors would like to thank also Safran Helicopter Engines which supported this study.

This project has received funding from the Clean Sky 2 Joint Undertaking under the European Union's Horizon 2020 research and innovation program under grant agreement $\mathrm{N}^{\circ} 820099$. This publication reflects only the author's view and the JU is not responsible for any use that may be made of the information it contains. 


\section{REFERENCES}

Baumgartner, M., Kameier, F., Hourmouziadis, J., (1995). Non-Engine Order Blade Vibration in a High Pressure Compressor.

Cambier, L., Gazaix, M., Heib, S, Plot, S., Poinot, M. et al., (2011). An Overview of the MultiPurpose elsAFlow Solver. AerospaceLab, p. 1-15

Gonzalez Diez, N., Smeulers, J. P. M., Tapinassi, L., Del Greco, A. S., Toni, L., (2014). Predictability of Rotating Stall and Surge in a Centrifugal Compressor Stage With Dynamic Simulations. Proceedings of ASME Turbo Expo 2014, Düsseldorf, Germany

Harley, P. X. L., Spence, S. W. T., Early, J., Filsinger, D. Dietrich, M., (2014). Inlet recirculation in automotive turbocharger centrifugal compressors. Proceedings of 11th International Conference on Turbocharger and Turbocharging

He, X., Zheng, X., (2018). Flow instability evolution in high pressure ratio centrifugal compressor with vaned diffuser. Experimental Thermal and Fluid Science, volume 98, p. 719-730

Inoue, M., Kuroumaru, M., Yoshida, S., Minami, T., Yamada, K., Furukawa, M., (2004). Effect of Tip Clearance on Stall Evolution Process in a Low-Speed Axial Compressor Stage. Proceedings of ASME Turbo Expo 2004, Vienna, Austria

Ishino, M., Iwakiri, Y., Bessho, A., Uchida, H., (1999). Effects of Variable Inlet Guide Vanes on Small Centrifugal Compressor Performance. Proceedings of ASME Turbo Expo 1999, Indianapolis, USA

Kameier, F., Neise, W., (1997). Experimental Study of Tip Clearance Losses and Noise in Axial Turbomachines and Their Reduction. Journal of Turbomachinery, volume 119, p. 460-471

Li, X., Spence, S., Wu, Y., (2018). The Interaction Between Inlet Guide Vanes and the Impeller Recirculating Flow in a Centrifugal Compressor and the Resulting Impact on Flow Range. Proceedings of ASME Turbo Expo 2018, Oslo, Norway

Mailach, R., Lehmann, I., Vogeler, K., (2001). Rotating Instabilities in an Axial Compressor Originating From the Fluctuating Blade Tip Vortex. Journal of Turbomachinery, volume 123

Marz, J., Hah, C., Neise, W., (2001). An Experimental and Numerical Investigation Into the Mechanisms of Rotating Instability. Proceedings of ASME Turbo Expo 2001, New Orleans, USA

Moënne-Loccoz, V., Trébinjac, I., Poujol, N., Duquesne, P., (2019). Low frequency stall modes of a radial vaned diffuser flow. Mechanics \& Industry, volume 20, p. 805

Moënne-Loccoz, V., Trébinjac, I., Poujol, N., Duquesne, P., (2020). Detection and analysis of an alternate flow pattern in a radial vaned diffuser. Int. J. Turbomach. Propuls. Power, volume 5

Pedersen, N., Larsen, P. S., Jacobsen, C. B., (2003). Flow in a Centrifugal Pump Impeller at Design and Off-Design Conditions-Part I: Particle Image Velocimetry (PIV) and Laser Doppler Velocimetry (LDV) Measurements. Journal of Fluids Engineering, volume 125, p. 61-72

Poujol, N., Trébinjac, I., Duquesne, P., (2020). Effects of inlet guide vanes on the performance and stability of an aeronautical centrifugal compressor. Proceedings of ASME Turbo Expo 2020, London, England

Schreiber, C., (2017). Inlet Recirculation in Radial Compressors. PhD thesis, University of Cambridge

Smith, B., (1994). A near wall model for the $k$ - $l$ two equation turbulence model. Fluid Dynamics Conference, Colorado Springs, USA

Stuart, C., Spence, S., Filsinger, D., Starke, A., Kim, S., (2017). Characterising the Influence of Impeller Exit Recirculation on Centrifugal Compressor Work Input. Proceedings of ASME Turbo Expo 2017, Charlotte, USA

Sun, Z., Zhou, W., Zheng, X., (2018). Instability detection of centrifugal compressors by means of acoustic measurements. Aerospace Science and Technology, volume 82-83, p. 628-635

Tamaki, H., Unno, M., Tanaka, R., Yamaguchi, S., Ishizu, Y., (2016). Enhancement of Centrifugal Compressor Operating Range by Control of Inlet Recirculation With Inlet Fins. Journal of Turbomachinery, volume 138 